\title{
Investigating Soil Strength and Stress-Strain Indices for Characterization of Erodibility for Soils in Some Selected Sites in Abia State
}

\author{
C.C. Egwuonwu, N.A.A. Okereke, K.O. Chilakpu, and S.O. Ohanyere
}

\begin{abstract}
In this study, initial soil strength indices (qu) and stress-strain characteristics namely failure strain (ef); area under the stress-strain curve up to failure (Is) and stress-strain modulus between no load and failure (Es) were investigated as potential indicators for characterizing the erosion resistance of two compacted soils namely sandy clay loam (SCL) and clay loam (CL) in some selected sites in Abia State, Nigeria. The unconfined compressive strength (used in obtaining strength indices) and stress-strain measurements were obtained as a function of moisture content in percentage (mc \%) and dry density (gd). Test were conducted over a range of $8 \%$ to $30 \%$ moisture content and $1.0 \mathrm{~g} / \mathrm{cm} 3$ to $2.0 \mathrm{~g} / \mathrm{cm} 3$ dry density at applied loads of 20,40,80, 160 and $320 \mathrm{kPa}$. Based on the results, it was found out that initial soil strength alone was not a good indicator of erosion resistance. For instance in the comparison of exponents of $\mathrm{mc} \%$ and $\mathrm{gd}$ for jet index or erosion resistance index ( $\mathrm{Ji})$ and the strength measurements, qu and Es (Table 7) agree in signs for $\mathrm{mc} \%$, but are opposite in signs for gd. Therefore there is an inconsistency in exponents making it difficult to develop a relationship between the strength parameters and $\mathrm{Ji}$ for this data set. In contrast, the exponents of $\mathrm{mc} \%$ and $\mathrm{gd}$ for $\mathrm{Ji}$ and ef and Is are opposite in signs (Table 7), there is potential for an inverse relationship. The measured stress-strain characteristics however, appeared to have potential in providing useful information on erosion resistance. The models developed for the prediction of the extent or the susceptibility of soils to erosion and subjected to sensitivity test on some selected sites as shown in table 8 achieved over $90 \%$ efficiency in their functions.
\end{abstract}

Keywords-Investigating, Characterization, Erodibility, Soil Strength, Stress-Strain, Indices, Soils, Selected Sites, Abia State, Nigeria.

\section{INTRODUCTION}

$\mathrm{T}$ HE intensive exploitation of soil for agricultural and capital construction in almost all branches of the national economies of most countries has gradually disturbed the natural soil cover and exposed the soil surface to the action of erosion agents i.e. the destructive effects of water and wind on

C.C. Egwuonwu, N.A.A. Okereke, K.O. Chilakpu, and S.O. Ohanyere are with Department of Agricultural Engineering, Federal University of Technology Owerri, Nigeria the soil surface, the removal of soil matter from the earth surface and its deposition in areas where the activities of these agents are decreasing $\{1\}$. It should be stressed that once a soil is lost it is difficult to replace within the foreseeable future as new soil formation is a slow process measured only on a geological time scale [2] hence the need for predicting the susceptibility of soils to erosion.

An accurate estimate of soil erodibility (the susceptibility or vulnerability of soil to erosion) is important to engineers involved in the design of water management projects. Defining soil erodibility, however, is a difficult task. This is because soil detachment is a complex function of both soil and eroding fluid properties $[3,4]$.

Predicting the susceptibility of a soil to erosion prior to a concentrated flow event is an important problem in many engineering projects such as irrigation, channels, levees, highways, railways, spillways, construction sites, mining area reclamation and land management:. In many of these engineering projects not only is the erodibility of the soil at the surface of interest, but also the erodibility with depth [5]. Earth spillways are an example in which erosion exposes different materials with depth and the erodibility of these materials is important in the performance of the spillways under concentrated flow conditions [5]. Measuring erodibility directly is often difficult. Therefore development of measurable soil parameters that indicate erodibility is attractive [6]

Soil strength indices have been a common soil parameter investigated for characterization of soil erodibility. Strength indices are commonly used because they can be easily and rapidly obtained, measured incrementally with depth and related to other soil parameters that affect soil erodibility such as dry density (gd) and water content (mc\%) [7]. Soil strength indices are also appealing because soil erosion is a function of the forces applied by the flow and resistance to erosion is offered by bonding forces between soil particles and other materials in the soil matrix [5]. Since the state of bonding is manifested in the soil strength, resistance to erosion should be characterized by the measurement of soil strength. Although soil strength indices have been used to characterize erodibility of soils, their success have been limited $[6 ; 8]$ hence the need for the use of more quantifiable parameters of soil such as strength and stress-strain characteristics. Unconfined 
compressive strength, triaxial shear test, vane shear strength, pocket penetrometer as well as other tests have been used to characterize soil strength [9].

The objectives of the study are: to measure and observe the relationship between soil strength indices, stress-strain characteristics and changes in moisture content and dry density for the selected sites and to develop models for predicting the susceptibility or extent of soils to erosion in the selected sites.

\section{MATERIALS AND METHODS}

\section{A. Study Area}

Characterisation of erodibility using soil strength and stressstrain indices was studied for some selected towns in Abia State Nigeria namely: Umuahia, Arochukwu and Nneato. These towns lie between latitude $5.3^{\circ} \mathrm{N}$ to $6.5^{\circ} \mathrm{N}$ and longitude $6.8^{\circ} \mathrm{E}$ to $8.1^{\circ} \mathrm{E}$ and are within the tropical rainforest zone. The study was carried out between November 2012 to March, 2013.

\section{B. Soil Materials}

The soils used in this study were a sandy clay loam (SCL) and a clay loam (CL) obtained from three (3) sites in Abia State, Nigeria namely Abia (1) - Umuahia; Abia (2) Arochukwu; Abia (3) - Nneato. The influence of compaction (mc\% and $\gamma_{\mathrm{d}}$ ) on resistance to erosion of these soils was reported in [10] and $[11 ; 12]$.

\section{Soil Preparation}

Soil samples were prepared by static load compaction. Thirty test samples of each soil were compacted using a device similar to a fixed ring consolidometer. Static pressure was applied to the soil by pneumatic bellows. Loads of 20, 40, 80, 160 and $320 \mathrm{kPa}$ were applied to the samples. The size of prepared soil sample was $445 \mathrm{~mm}$ in diameter and the final height varied from $100 \mathrm{~mm}$ to $200 \mathrm{~mm}$ depending on the load applied and the mc\%. Samples were compacted at various mc\% ranging from 8 to $30 \%$ for each load. The soils were wet by spraying to various mc\% mixed thoroughly and stored in polyethylene bags for 24 hours to allow the water to permeate through the soil.

\section{Soil Testing}

Test was conducted on the compacted samples. Strength and stress-strain values were measured with the unconfined compression test.

The unconfined compressive tests were conducted in accordance with ASTM D2166. In addition to the unconfined compressive strength (qu), stress-strain characteristics namely failure strain (ef), area under the stress-strain curve up to failure (Is), and stress-strain modulus between no load and failure (Es) were determined for the unconfined compressive test. Unconfined compressive tests were continued until the load values decreased with increasing strain or until $20 \%$ strain was reached.

The samples of soil [sandy clay loam (SCL) and clay loam
(CL)] were tested for resistance to erodibility using a submerged jet testing device. Water was fed under a constant head of $0.91 \mathrm{~m}$, through a circular nozzle, $13 \mathrm{~mm}$ in diameter, at a set height of $0.22 \mathrm{~m}$ above a level bed of prepared soil. The rate of scour was monitored with time. The erosion resistance of the samples was based on a jet index ( Ji). The lower the $\mathrm{Ji}$ values the less erosion occurred, and the more resistant the material [13].

\section{E. Data Analysis}

A comparison of nonlinear power curve regression fits or power equation or models for jet index $\left(\mathrm{J}_{\mathrm{i}}\right)$, failure strain $\left(\varepsilon_{\mathrm{f}}\right)$, area under the stress-strain curve up to failure $\left(I_{s}\right)$, unconfined compressive strength $\left(\mathrm{q}_{\mathrm{u}}\right)$ and stress-strain modulus between no load and failure $\left(E_{s}\right)$ versus the variables mc\% and $\gamma_{d}$ was developed. The non linear power curve function served as potential for functional relationships.

Multiple Linear Regressions in conjunction with NaïveGauss Elimination Method and Gauss-Jordan Matrix Inverses were used to obtain the models.

The coefficient of determination $\left(\mathrm{r}^{2}\right)$ was computed for each developed model to ascertain the level of accuracy or exactness of each model.

\section{RESULTS}

The strength test and stress-strain results as well as the jet index result for SCL and CL soils are shown in Tables $1-6$ for the sites selected in Abia State. The comparison of nonlinear power curve regression fits for $\mathrm{J}_{\mathrm{i}}, \varepsilon_{\mathrm{f}}, \mathrm{I}_{\mathrm{s}}, \mathrm{q}_{\mathrm{u}}$, and $\mathrm{E}_{\mathrm{s}}$ versus the variables $\mathrm{mc} \%$ and $\gamma_{\mathrm{d}}$ is shown in Table 7. The prediction of the extent or the susceptibility of soils to erosion on some selected sites using the $\mathrm{J}_{\mathrm{i}}$ models developed is illustrated in Table 8.

The predicted $J_{i}$ versus $q_{u}$ and $J_{i}$ versus $\varepsilon_{f}$ for SCL and CL soils (Abia) in Figure 1 and Figure 2 respectively.

TABLE I

STRENGTH AND STRESS-STRAIN INDICES FOR SCL SOIL AS A FUNCTION OF MC\% AND $\gamma_{D}$ F FOR ABIA STATE (1)UNITS

\begin{tabular}{cccccc}
\hline $\mathbf{m c}(\boldsymbol{\%})$ & $\begin{array}{c}\boldsymbol{\gamma}_{\mathbf{d}} \\
\left(\mathbf{g} \mathbf{c m}^{3}\right)\end{array}$ & $\begin{array}{c}\mathbf{q u}_{\mathbf{u}} \\
(\mathbf{k P a})\end{array}$ & $\boldsymbol{\varepsilon}_{\mathbf{f}}$ & $\left.\mathbf{I}_{\mathbf{s}} \mathbf{( k P a}\right)$ & $\begin{array}{c}\mathbf{E}_{\mathbf{s}} \\
(\mathbf{k P a})\end{array}$ \\
$12.2^{* *}$ & 1.24 & 05 & 0.010 & 0.20 & 400 \\
13.8 & 1.28 & 02 & 0.010 & 0.20 & 300 \\
15.6 & 1.30 & 06 & 0.020 & 0.30 & 500 \\
16.0 & 1.40 & 12 & 0.040 & 0.40 & 500 \\
18.0 & 1.58 & 18 & 0.120 & 2.00 & 300 \\
20.0 & $1.60^{*}$ & 20 & 0.200 & 3.00 & 100 \\
21.0 & 1.62 & 18 & 0.200 & 3.00 & 100 \\
8.0 & 1.20 & 15 & 0.010 & 0.16 & 400 \\
10.0 & 1.24 & 20 & 0.010 & 0.20 & 500 \\
$12.0^{* *}$ & 1.30 & 25 & 0.020 & 0.25 & 600 \\
15.0 & 1.50 & 30 & 0.040 & 0.80 & 800 \\
15.8 & $1.60^{*}$ & 30 & 0.070 & 1.50 & 800 \\
$17 . .1$ & 1.66 & 30 & 0.160 & 4.00 & 300 \\
17.7 & 1.70 & 40 & 0.160 & 4.50 & 300 \\
18.0 & 1.70 & 40 & 0.200 & 5.50 & 200 \\
18.7 & 1.70 & 40 & 0.200 & 5.50 & 100 \\
19.8 & 1.70 & 40 & 0.200 & 6.00 & 100 \\
8.0 & 1.30 & 10 & 0.010 & 0.20 & 1000 \\
12.0 & 1.40 & 30 & 0.010 & 0.40 & 1200 \\
13.8 & $1.60^{*}$ & 40 & 0.050 & 1.50 & 1200 \\
15.0 & 1.70 & 50 & 0.100 & 3.00 & 800 \\
\hline
\end{tabular}




\begin{tabular}{cllllr}
\hline 15.6 & 1.80 & 70 & 0.110 & 4.00 & 1000 \\
16.2 & 1.82 & 90 & 0.120 & 6.00 & 500 \\
8.0 & 1.40 & 25 & 0.010 & 0.30 & 1700 \\
10.0 & 1.44 & 30 & 0.020 & 0.40 & 1800 \\
$12.0^{* *}$ & $1.60^{*}$ & 50 & 0.030 & 1.50 & 1800 \\
14.0 & 1.85 & 80 & 0.080 & 5.00 & 1000 \\
8.0 & 1.58 & 60 & 0.010 & 0.60 & 2900 \\
10.0 & 1.65 & 70 & 0.010 & 1.00 & 2800 \\
$12.0^{* *}$ & 1.70 & 80 & 0.030 & 2.00 & 2400 \\
\hline
\end{tabular}

TABLE II

STRENGTH AND STRESS-STRAIN INDICES FOR CL SOIL AS A FUNCTION OF MC\% AND $\gamma_{D}$ FOR ABIA STATE (2)

\begin{tabular}{cccccc}
\hline $\mathbf{m c}(\boldsymbol{\%})$ & $\begin{array}{c}\boldsymbol{\gamma}_{\mathbf{d}} \\
\left(\mathbf{g} / \mathbf{c m}^{\mathbf{3}}\right)\end{array}$ & $\begin{array}{c}\mathbf{q u}_{\mathbf{u}} \\
(\mathbf{k P a})\end{array}$ & $\boldsymbol{\varepsilon}_{\mathbf{f}}$ & $\mathbf{I}_{\mathbf{s}} \mathbf{( k P a )}$ & $\begin{array}{c}\mathbf{E}_{\mathbf{s}} \\
(\mathbf{k P a})\end{array}$ \\
14.4 & 1.05 & 10 & 0.008 & 0.15 & 500 \\
15.8 & 1.10 & 10 & 0.010 & 0.15 & 530 \\
17.8 & 1.18 & 10 & 0.015 & 0.20 & 600 \\
20.4 & 1.26 & 12 & 0.038 & 0.40 & 500 \\
$21.0^{* *}$ & 1.30 & 10 & 0.040 & 0.50 & 400 \\
21.8 & 1.35 & 08 & 0.040 & 0.60 & 300 \\
11.2 & 1.10 & 10 & 0.006 & 0.12 & 500 \\
13.6 & 1.15 & 15 & 0.010 & 0.18 & 800 \\
15.8 & 1.19 & 15 & 0.012 & 0.20 & 700 \\
17.0 & 1.25 & 18 & 0.020 & 0.35 & 900 \\
$21.0 * *$ & $1.42 *$ & 18 & 0.060 & 1.00 & 500 \\
21.8 & 1.55 & 38 & 0.120 & 4.00 & 400 \\
9.4 & 1.18 & 15 & 0.008 & 0.15 & 800 \\
12.0 & 1.20 & 18 & 0.010 & 0.20 & 1000 \\
14.0 & 1.23 & 20 & 0.010 & 0.25 & 1200 \\
17.0 & 1.35 & 25 & 0.020 & 0.32 & 1400 \\
17.8 & $1.42^{*}$ & 38 & 0.032 & 0.80 & 1600 \\
21.0 & 1.55 & 50 & 0.080 & 4.00 & 800 \\
22.0 & 1.60 & 40 & 0.160 & 6.00 & 300 \\
9.0 & 1.32 & 35 & 0.010 & 0.25 & 1900 \\
11.7 & 1.38 & 40 & 0.015 & 0.30 & 2000 \\
13.6 & $1.42^{*}$ & 35 & 0.020 & 0.40 & 1800 \\
17.8 & 1.50 & 65 & 0.030 & 1.00 & 2000 \\
19.8 & 1.60 & 70 & 0.120 & 4.00 & 1000 \\
& 1.70 & 80 & 0.160 & 8.00 & 600 \\
$21.0 * *$ & & & & & \\
12.8 & $1.43 *$ & 70 & 0.010 & 0.35 & 3000 \\
16.4 & 1.61 & 100 & 0.060 & 4.00 & 2200 \\
18.0 & 1.65 & 110 & 0.080 & 6.00 & 2000 \\
19.4 & 1.68 & 115 & 0.120 & 7.00 & 700 \\
20.2 & 1.72 & 120 & 0.140 & 8.00 & 500 \\
\hline & & & & & \\
& & & &
\end{tabular}

TABLE III

STRENGTH AND STRESS-STRAIN INDICES FOR CL SOIL AS A FUNCTION OF MC\%

\begin{tabular}{cccccc}
\multicolumn{6}{c}{ AND $\gamma_{\mathrm{D}}$ FOR ABIA STATE (3) } \\
\hline $\mathbf{m c}(\boldsymbol{\%})$ & $\begin{array}{c}\boldsymbol{\gamma}_{\mathbf{d}} \\
\left(\mathbf{g} / \mathbf{c m}^{\mathbf{3}}\right)\end{array}$ & $\begin{array}{c}\mathbf{q u}_{\mathbf{u}} \\
(\mathbf{k P a})\end{array}$ & $\boldsymbol{\varepsilon}_{\mathbf{f}}$ & $\mathbf{I}_{\mathbf{s}}(\mathbf{k P a})$ & $\begin{array}{c}\mathbf{E}_{\mathbf{s}} \\
(\mathbf{k P a})\end{array}$ \\
9.5 & 1.10 & 10 & 0.010 & 0.02 & 450 \\
12.0 & 1.15 & 13 & 0.012 & 0.12 & 700 \\
14.0 & 1.20 & 16 & 0.015 & 0.19 & 900 \\
17.0 & 1.25 & 18 & 0.018 & 0.24 & 980 \\
18.5 & 1.30 & 19 & 0.032 & 0.39 & 800 \\
20.0 & 1.35 & 19 & 0.040 & 0.70 & 600 \\
22.0 & 1.40 & 12 & 0.080 & 1.60 & 250 \\
9.0 & 1.15 & 12 & 0.001 & 0.08 & 500 \\
10.6 & 1.20 & 17 & 0.001 & 0.16 & 900 \\
11.7 & 1.25 & 19 & 0.002 & 0.20 & 1200 \\
13.6 & 1.30 & 26 & 0.003 & 0.28 & 1500 \\
17.8 & 1.37 & 30 & 0.034 & 0.50 & 1350 \\
19.8 & $1.45^{*}$ & 36 & 0.058 & 1.40 & 800 \\
$21.0^{* *}$ & 1.52 & 38 & 0.090 & 3.20 & 470 \\
10.0 & 1.20 & 16 & 0.012 & 0.15 & 900 \\
12.5 & 1.26 & 20 & 0.014 & 0.23 & 1370 \\
15.0 & 1.35 & 32 & 0.017 & 0.37 & 1600 \\
17.0 & $1.45^{*}$ & 40 & 0.034 & 0.80 & 1700 \\
& 1.55 & 40 & 0.100 & 3.90 & 480 \\
$21.0^{* *}$ & 1.60 & 40 & 0.150 & 6.00 & 250 \\
\hline
\end{tabular}

\begin{tabular}{cllllr}
\hline 22.0 & & & & & \\
12.0 & 1.30 & 26 & 0.013 & 0.24 & 1500 \\
14.5 & $1.45^{*}$ & 50 & 0.019 & 0.56 & 2300 \\
16.5 & 1.52 & 54 & 0.037 & 1.20 & 2000 \\
18.0 & 1.60 & 63 & 0.070 & 3.80 & 1800 \\
21.0 & 1.70 & 80 & 0.150 & 8.00 & 490 \\
$* *$ & & & & & \\
13.0 & $1.45^{*}$ & 54 & 0.010 & 0.50 & 2500 \\
16.5 & 1.58 & 80 & 0.040 & 2.40 & 2400 \\
18.0 & 1.64 & 88 & 0.071 & 4.00 & 1800 \\
19.4 & 1.70 & 93 & 0.120 & 6.80 & 1050 \\
$21.0^{* *}$ & 1.75 & 100 & 0.170 & 8.80 & 500 \\
\hline
\end{tabular}

TABLE IV

VALUES OF $\mathrm{J}_{1}$ FOR SCL SOIL AS A FUNCTION OF MC\% AND $\gamma_{\mathrm{D}}$ FOR ABIA STATE $(1)$

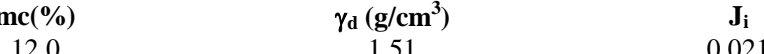

12.0

12.7

11.8

10.6

11.3

13.0

$13 . .9 * *$

13.2

12.1

13.1

15.5

14.5

13.2

17.0

16.2

14.6

13.8 **

15.7

14.6

16.4

15.0

14.4

17.2

15.1

13.9 **

1.51

1.35

1.60

1.80

$1.72 * * *$

1.49

1.36

1.50

$1.72 * * *$

1.64

1.35

1.51

$1.72 * * *$

1.40

1.55

1.73 ***

1.84

1.80

1.87

1.82

1.86

1.88

1.84

1.87

1.90

0.021

0.020

0.020
0.020

0.020

0.019

0.017

0.016

0.016

0.016

0.014

0.011

0.011

0.011

0.009

0.007

0.007

0.007

0.005

0.005

0.004

0.004

0.004

0.003

0.003

0.003

TABLE V

VALUES OF J J FOR CL SOIL AS A FUNCTION OF MC\% AND $\gamma_{\mathrm{D}}$ FOR ABIA STATE (2)

\begin{tabular}{lcc}
$\mathbf{m c}(\%)$ & $\gamma_{\mathbf{d}}\left(\mathbf{g} / \mathbf{c m}^{3}\right)$ & $\mathbf{J}_{\mathbf{i}}$ \\
17.0 & 1.24 & 0.014 \\
15.6 & 1.33 & 0.014 \\
14.3 & 1.46 & 0.014 \\
13.0 & 1.54 & 0.014 \\
$12.9^{* *}$ & 1.60 & 0.014 \\
10.1 & $1.71^{* * *}$ & 0.014 \\
17.3 & 1.28 & 0.011 \\
15.3 & 1.36 & 0.011 \\
13.6 & 1.42 & 0.011 \\
$12.8^{* *}$ & 1.65 & 0.011 \\
11.2 & 1.68 & 0.011 \\
10.3 & 1.75 & 0.011 \\
18.2 & 1.33 & 0.008 \\
16.8 & 1.45 & 0.008 \\
15.0 & 1.51 & 0.008 \\
14.1 & 1.64 & 0.008 \\
$12.8 * *$ & $1.70^{* * *}$ & 0.008 \\
10.6 & 1.75 & 0.008 \\
16.3 & 1.54 & 0.007 \\
19.0 & 1.61 & 0.006 \\
20.3 & 1.53 & 0.004 \\
18.5 & 1.60 & 0.004 \\
16.2 & 1.65 & 0.004 \\
14.8 & 1.72 & 0.004 \\
21.8 & $1.70^{* * *}$ & 0.003 \\
19.0 & 1.72 & 0.003 \\
16.5 & 1.76 & 0.003 \\
\hline & &
\end{tabular}


TABLE VI

\begin{tabular}{ccc} 
VALUES OF $\mathbf{J}_{\mathrm{I}}$ FOR SCL AS A FUNCTION FF MC\% AND $\gamma_{\mathrm{D}}$ FOR ABIA STATE (3) \\
\hline $\mathbf{m c}(\mathbf{\%})$ & $\boldsymbol{\gamma}_{\mathbf{d}}\left(\mathbf{g} / \mathbf{c m}^{\mathbf{3}}\right)$ & $\mathbf{J}_{\mathbf{i}}$ \\
11.9 & 1.38 & 0.022 \\
12.6 & 1.32 & 0.021 \\
11.4 & $1.60^{* * *}$ & 0.021 \\
10.0 & 1.88 & 0.021 \\
12.8 & 1.45 & 0.019 \\
$13.0^{* *}$ & 1.40 & 0.018 \\
12.2 & $1.60^{* * *}$ & 0.018 \\
11.0 & 1.80 & 0.018 \\
14.0 & 1.29 & 0.017 \\
11.4 & 1.78 & 0.017 \\
14.2 & 1.30 & 0.016 \\
$13.0^{* *}$ & 1.53 & 0.016 \\
11.2 & 1.86 & 0.016 \\
16.1 & 1.36 & 0.012 \\
14.0 & $1.60^{* * *}$ & 0.012 \\
12.4 & 1.85 & 0.012 \\
18.1 & 1.42 & 0.009 \\
13.6 & 1.83 & 0.009 \\
18.7 & 1.45 & 0.008 \\
16.1 & $1.60^{* * *}$ & 0.008 \\
12.4 & 1.95 & 0.008 \\
18.4 & 1.69 & 0.006 \\
14.8 & 1.82 & 0.006 \\
$13.0^{* *}$ & 1.90 & 0.006 \\
14.6 & 1.88 & 0.005 \\
17.1 & 1.84 & 0.004 \\
$13.0^{* *}$ & 1.98 & 0.004 \\
& & \\
\hline
\end{tabular}

TABLE VII

POWER CURVE FunCtions OF PARAMETERS $\mathrm{J}_{\mathrm{I}}, \mathrm{Q}_{\mathrm{U}}, \varepsilon_{\mathrm{F}}, \mathrm{I}_{\mathrm{S}}$, AND $\mathrm{E}_{\mathrm{S}}$ FOR SCL AND CL SOILS ABIA STATE

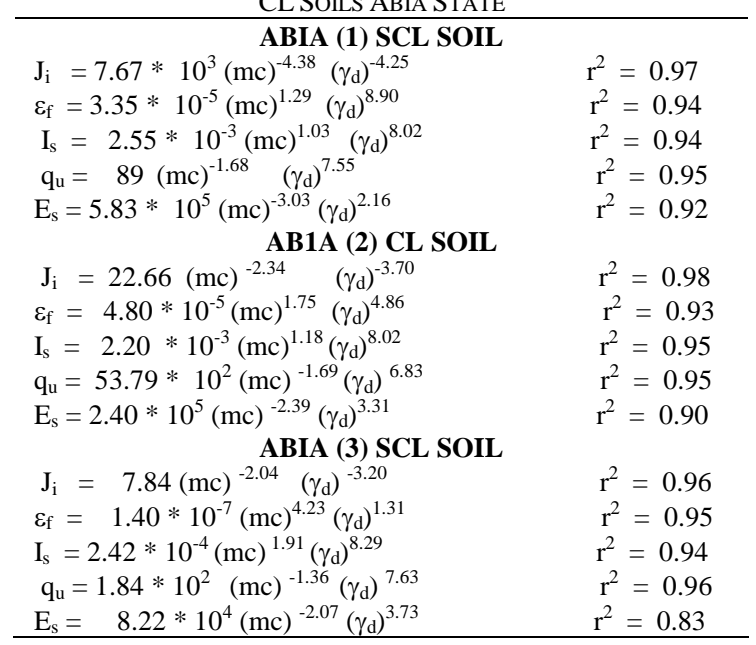

TABLE VIII

PREDICTION OF THE EXTENT OR THE SUSCEPTIBILITY OF SOILS TO EROSION ON SOME SELECTEd Sites USING THE $\mathrm{J}_{\mathrm{I}}$ MODEl DEVELOPED FOR ABIA STATE

\begin{tabular}{cccc}
\hline Location & Average mc\% & Average $\left(\gamma_{\mathbf{d}}\right)$ & $\mathbf{J}_{\mathbf{i}}$ Model \\
Abia (1) - A & 14.70 & 1.28 & 0.021 \\
Abia (1)-B & 16.00 & 1.85 & 0.003 \\
Abia (2)-A & 14.10 & 1.35 & 0.020 \\
Abia (2) - B & 18.50 & 1.75 & 0.002 \\
Abia (3) - A & 11.80 & 1.62 & 0.020 \\
Abia (3) - B & 15.50 & 1.33 & 0.014 \\
\hline
\end{tabular}

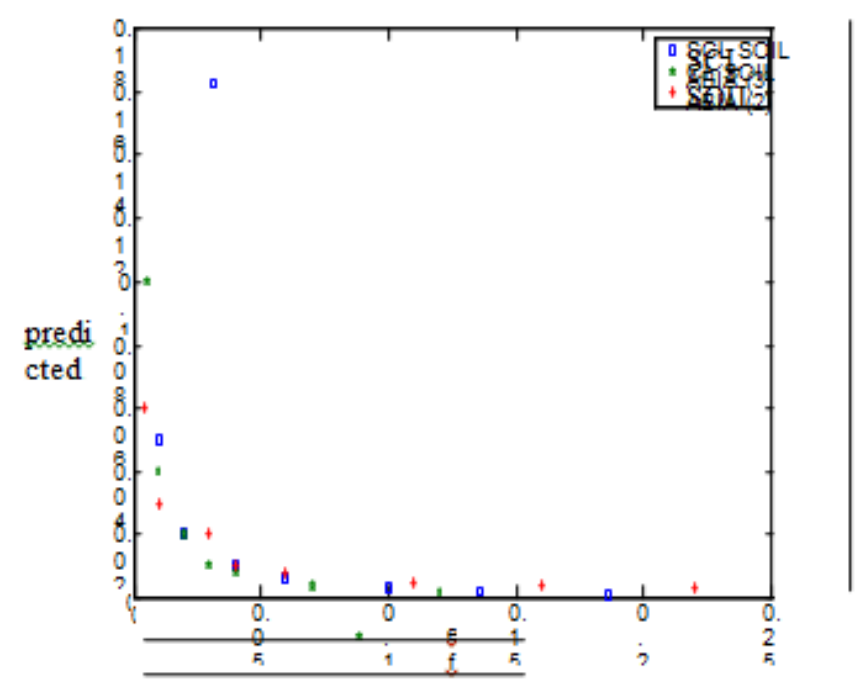

Fig. 1: Combined Data for SCL and CL Soils for Predict ted Ji vs ef, Abia State

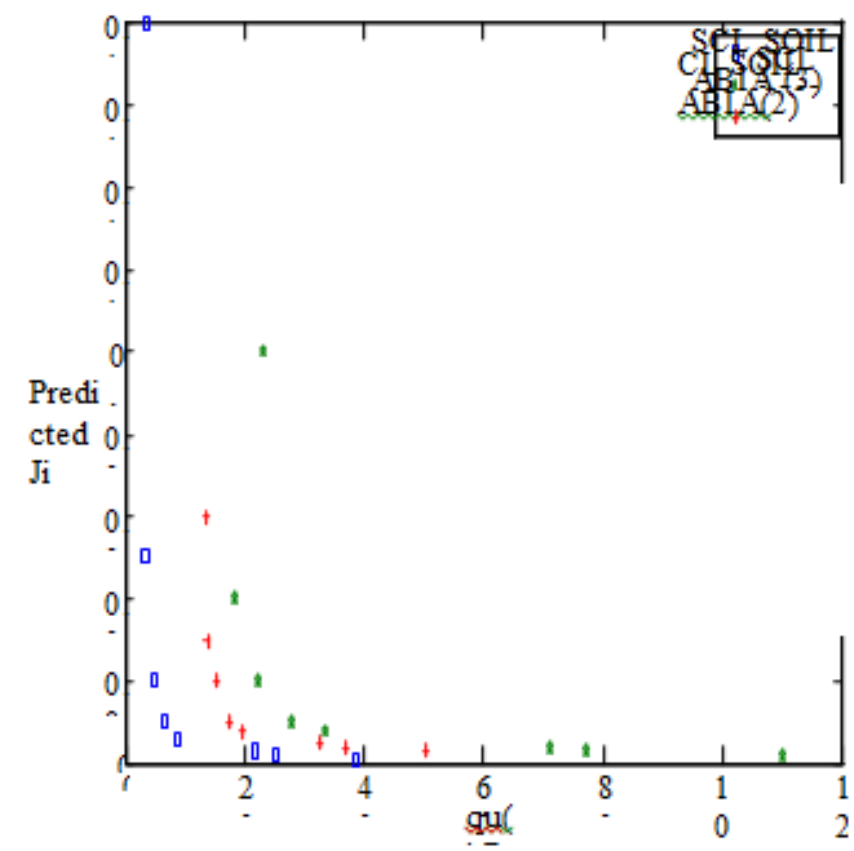

Fig. 2: Combined Data for SCL and CL Soil for predicted Ji Vs qu, Abia state

\section{A. Discussion}

The strength indices $\left(\mathrm{q}_{\mathrm{u}}\right)$ for the SCL and CL soils for the sites selected followed similar trends (Tables $1-3$ ). Strength indices increased as the $\gamma_{\mathrm{d}}$ increased for a given mc and as the mc decreased for a given $\gamma_{\mathrm{d}}$ (the asterixed values $*$ and $* *$ in Tables 1-3). It was observed that $\mathrm{q}_{\mathrm{u}}, \varepsilon_{\mathrm{f}}, \mathrm{I}_{\mathrm{s}}$ and $\mathrm{E}_{\mathrm{s}}$ increased as $\gamma_{\mathrm{d}}$ increased. The values of $\mathrm{q}_{\mathrm{u}}$ and $\mathrm{E}_{\mathrm{s}}$ decreased as $\mathrm{mc} \%$ increased for a constant $\gamma_{\mathrm{d}}$, whereas $\varepsilon_{\mathrm{f}}$, and $\mathrm{I}_{\mathrm{s}}$ tended to increase (the asterixed values $*$ and $* *$ in Tables 1-3). . At low $\mathrm{mc} \%$, the soil tended to fail by brittle fracture. At high $\mathrm{mc} \%$, the soil failed plastically.

The relationship of $\varepsilon_{f}, I_{s}$ and $E_{s}$ to $\gamma_{d}$ and mc\% for the same set of samples shown in the tables listed for strength indices are shown in Tables: $1-3$. The $\mathrm{E}_{\mathrm{s}}$ values were observed to have similar relationship as the strength indices $\left(\mathrm{q}_{\mathrm{u}}\right)$ had to $\gamma_{\mathrm{d}}$ (Tables $1-3$ ). Soil strength indices decreased with increases 
in $\mathrm{mc} \%$ (the asterixed values $*$ and $* *$ in Tables $1-3$ ), whereas the resistance to erosion increased with increases in $\mathrm{mc} \%$ within the same range ((the asterixed values $* *$ and $* * *$ in Tables 4-6). The conclusion is that the soil strength indices alone, although affected by $\mathrm{mc} \%$ and $\gamma_{\mathrm{d}}$, would make poor erosion characterization indicators.

The stress-strain characteristics $\varepsilon_{\mathrm{f}}$ and $\mathrm{I}_{\mathrm{s}}$, tended to increase with increases in $\gamma_{\mathrm{d}}$ and mc\% (Tables 1-3) and these concur with that of the erosion resistance index $\left(\mathrm{J}_{\mathrm{i}}\right)$ (Tables 4-6). Whereas $E_{\mathrm{s}}$ tended to increase with $\gamma_{\mathrm{d}}$ and decrease with mc\%. Based on these test results, $\mathrm{E}_{\mathrm{s}}$ has the same potential problems as strength indices, $\mathrm{q}_{\mathrm{u}}$. However, $\varepsilon_{\mathrm{f}}$ and $\mathrm{I}_{\mathrm{s}}$ have potential for indicating erosion resistance of a soil.

A comparison of nonlinear power curve regression fits for $\mathrm{J}_{\mathrm{i}}, \varepsilon_{\mathrm{f}}, \mathrm{I}_{\mathrm{s}}, \mathrm{q}_{\mathrm{u}}$, and $\mathrm{E}_{\mathrm{s}}$ versus the variables $\mathrm{mc} \%$ and $\gamma_{\mathrm{d}}$ are shown in Table 7. The nonlinear power curve function served as potential for functional relationships and was consistently a good fitting function in all cases and allowed comparison between parameters.

The exponents of $\mathrm{mc} \%$ and $\gamma_{\mathrm{d}}$ indicate their functional relationship to $\mathrm{J}_{\mathrm{i}}, \varepsilon_{\mathrm{f}}, \mathrm{I}_{\mathrm{s}}, \mathrm{q}_{\mathrm{u}}$, and $\mathrm{E}_{\mathrm{s}}$. Based on the exponents $\mathrm{J}_{\mathrm{i}}$ decreases as mc\% increases holding $\gamma_{\mathrm{d}}$ constant. his comparison indicates that even though the exponents of $\mathrm{mc} \%$ and $\gamma_{\mathrm{d}}$ for $\mathrm{J}_{\mathrm{i}}$ and $\varepsilon_{\mathrm{f}}$ and $\mathrm{I}_{\mathrm{s}}$ are opposite in signs, there is potential for an inverse relationship. In contrast, the comparison of the exponents for $\mathrm{mc} \%$ and $\gamma_{\mathrm{d}}$ for $\mathrm{J}_{\mathrm{i}}$ and the strength measurements, $\mathrm{q}_{\mathrm{u}}$ and $\mathrm{E}_{\mathrm{s}}$ agree in signs for $\mathrm{mc} \%$, but are opposite in signs for $\gamma_{\mathrm{d}}$. Therefore, there is an inconsistency in exponents making it difficult to develop a relationship between the strength parameters and $\mathrm{J}_{\mathrm{i}}$ for this data set.

The jet index $\left(\mathrm{J}_{\mathrm{i}}\right)$ test results and the strength $\left(\mathrm{q}_{\mathrm{u}}\right)$ and stressstrain $\left(\varepsilon_{\mathrm{f}}\right)$ test results are independent data sets, a prediction of $\mathrm{J}_{\mathrm{i}}$ can be made for the strength and stress-stain data using the functional relationships in Table 7 for the SCL and CL soil. As an example of the potential relationships for $J_{i}$ versus $\varepsilon_{f}$ and $\mathrm{q}_{\mathrm{u}}$ a comparison of the predicted $\mathrm{J}_{\mathrm{i}}$ versus $\varepsilon_{\mathrm{f}}$ and predicted $\mathrm{J}_{\mathrm{i}}$ versus $\mathrm{q}_{\mathrm{u}}$ for Abia State is shown in Figures 1 and Figures 2 respectively for SCL and CL soil.

These plots show that there does appear to be a general trend as $\mathrm{q}_{\mathrm{u}}$ increases $\mathrm{J}_{\mathrm{i}}$ decreases but there is quite a bit of scatter. For a parameter to be effective in predicting erodibility, it must also be consistent between soils. Combing the data for predicted $\mathrm{J}_{\mathrm{i}}$ versus $\varepsilon_{\mathrm{f}}$ brings the data for SCL and CL soils together (Figure 1). However, combining the data for $\mathrm{q}_{\mathrm{u}}$ versus $\mathrm{J}_{\mathrm{i}}$ does not bring the data together (Figure 2).

Using the erosion prediction model $\mathbf{J}_{\mathrm{i}}$ obtained for the three sites in Abia State, two locations in each of the sites were each tested for the mc\% and $\gamma_{\mathrm{d}}$. The two sites included one that had visibly undergone erosion (A) and one that had not visibly under gone or partially undergone erosion (B). The parameters $\mathrm{mc} \%$ and $\gamma_{\mathrm{d}}$ were obtained at random locations (20) on the site. The average values of the parameter were imputed in the $\mathrm{J}_{\mathrm{i}}$ model to ascertain the extent of or the susceptibility of soils to erosion and to also verify the efficacy or exactness of the model obtained. This is shown in table 8 .
Based on the jet index $\left(\mathrm{J}_{\mathrm{i}}\right)$, a highly erodibile soil will have a $\mathrm{J}_{\mathrm{i}}$ of approximately 0.020 whilst an erosion resistant soil will have a $\mathrm{J}_{\mathrm{i}}$ of approximately 0.002 . From table 8; Abia $1 \mathrm{~A}$, Abia $2 \mathrm{~A}$ and Abia $3 \mathrm{~A}$ had $\mathrm{J}_{\mathrm{i}}$ values close to 0.020 or slightly above it. This explains the adverse extent of erosion on these soil to the extent it was glaringly visible. Abia 1B, Abia 2B and Abia $3 \mathrm{~B}$ had $\mathrm{J}_{\mathrm{i}}$ values close to 0.002 or slightly above it with no visible signs of erosion. These soils are still erosion resistant.

\section{B. Conclusion and Recommendations}

The soil strength indices $\left(\mathrm{q}_{\mathrm{u}}\right)$ for SCL and CL soil in the sites increased with increases in dry density $\left(\gamma_{\mathrm{d}}\right)$ (Tables 1 to 3). The resistance to erosion $\left(\mathrm{J}_{\mathrm{i}}\right)$ of the SCL and CL soils in the region also increased with increases in $\gamma_{d}$ (Tables 4 to 6). $\mathrm{q}_{\mathrm{u}}$ decreased with increases in moisture content (mc\%) (Tables $1-3)$, whereas $J_{i}$ increased with increases in $m c \%$ within the same range (Tables 4-6).

Soil strength $\left(\mathrm{q}_{\mathrm{u}}\right)$ and erodibility $\left(\mathrm{J}_{\mathrm{i}}\right)$ are both affected by mc\% and $\gamma_{\mathrm{d}}$, but not necessarily in the same functional manner (Table 7). The comparison of the exponents for mc\% and $\gamma_{d}$ for $\mathrm{J}_{\mathrm{i}}$ and the strength measurements; $\mathrm{q}_{\mathrm{u}}$ and $\mathrm{E}_{\mathrm{s}}$ agree in signs for $\mathrm{mc} \%$, but are opposite in signs for $\gamma_{\mathrm{d}}$. Therefore, there is an inconsistency in exponents making it difficult to develop a relationship between the strength parameters and $\mathrm{J}_{\mathrm{i}}$ for the data set.

Furthermore, the predicted $\mathrm{J}_{\mathrm{i}}$ versus $\mathrm{q}_{\mathrm{u}}$ for SCL and CL (Figures 2) soils does not indicate potential for a relationship between soils. For a parameter to be effective in predicting erodibility it must also be consistent between soils. However, the combined data for $\mathrm{J}_{\mathrm{i}}$ and $\mathrm{q}_{\mathrm{u}}$ does not bring the data together (Figure 2). This does not discard soil strength as a potential indicator, but it does indicate that it should not be solely relied upon for prediction of soil erodibility.

The results from compacted samples of SCL and CL soils indicate that stress-strain characteristics namely failure strain $\left(\varepsilon_{\mathrm{f}}\right)$ and area under the stress strain curve up to failure $\left(\mathrm{I}_{\mathrm{s}}\right)$ are helpful in predicting erodibility. The stress-strain indices $\left(\varepsilon_{\mathrm{f}}\right.$ and $I_{s}$ ) increased with increases in both $\gamma_{d}$ and mc\% (Tables 1 to 3$)$. The resistance to erosion $\left(\mathrm{J}_{\mathrm{i}}\right)$ of the SCL and CL soil also increased with increase in both $\gamma_{\mathrm{d}}$ and $\mathrm{mc} \%$ within the same range (Tables 4 to 6 ).

$\varepsilon_{\mathrm{f}}$ and $\mathrm{I}_{\mathrm{s}}$ had similar functional relationships to $\mathrm{J}_{\mathrm{i}}$ (Table 7). Even though, the exponents of $\mathrm{mc} \%$ and $\gamma_{\mathrm{d}}$ for $\mathrm{J}_{\mathrm{i}}$, and $\varepsilon_{\mathrm{f}}$ and $\mathrm{I}_{\mathrm{s}}$ are opposite in signs, there is potential for an inverse relationship. The predicted $\mathrm{J}_{\mathrm{i}}$ versus $\varepsilon_{\mathrm{f}}$ for SCL and CL soils (Figure 1) indicate potential for a relationship between stressstrain and erodibility for a soil and between soils. The combined data for predicted $\mathrm{J}_{\mathrm{i}}$ versus $\varepsilon_{\mathrm{f}}$ brings the data for SCL and CL soils together (Figure 1). These results indicate that stress-strain characteristics should be included alongside strength indices in studies when developing relationships between soil erodibility and other soil parameters.

The models developed for the prediction of the extent or the susceptibility of soils to erosion and subjected to sensitivity test on some selected sites as shown in Table 8 achieved over $90 \%$ efficiency in their functions.

From the discoveries made in this project, it is appropriate to recommend the following: 
- Similar studies should be extended to other areas in the country that are prone to erosion in order to develop models that will ascertain the susceptibility or extent of soils to erosion. Since the control of erosion is capital intensive, early detection will minimize cost and ultimately save the environment from its menace.

- Studies in soil erosion are usually intensive and expensive in terms of finance. Government through institutions, agencies and parastatals should make available adequate funds to sustain such studies. With proper funding, results of such studies will go a long way in totally annihilating the menace of soil erosion in our environment if sincerely implemented?

- Soil strength should not be solely relied upon for measuring erodibility of soils. However, other parameters i.e. stressstrain characteristics etc should be included alongside strength indices when developing relationships between soil erodibility and other soil parameters.

\section{REFERENCES}

[1] G.E.K. Ofomata, " The management of soil erosion problems in S.E. Nigeria.",Proceedings of the International Symposium on Erosion in Southern Eastern Nigeria, 1988, pp.13 - 15.

[2] O.I. Abarikwu, "The challenges of erosion in Imo State", Proceedings of the International Symposium on Erosion in Southern Eastern Nigeria, 1988, pp. $116-119$.

[3] C. C. Egwuonwu, and A. P. Uzoije, "A comparative analysis of coconut, palmfrond and palm stem fibres as erosion control materials on embankments". Asset International Journal, University of Agriculture Abeokuta, Nigeria, 2009, pp. 1 - 7 .

[4] J. O. Akintola, ''Determination of rainfall erosivity for different agroecological zones in Nigeria". Unpublished M. Sc Thesis, Department of Agric. Engrg, University of Ibadan, 2001.

[5] G. J. Hanson, 'Investigating soil strength and stress-strain indices to characterize Erodibility. Trans of ASAE, 1996. 39 (3): 883 - 890. http://dx.doi.org/10.13031/2013.27573

[6] W. J. Elliot, L. J. Olivieri, J. M. Laflen and K. D. Kohl, '’Predicting soil erodibility from strength measurements. ASAE paper no. 90-2009. St. Joseph Mich., 1990.

[7] C. C. Egwuonwu and N. A .A. Okereke, "Characterisation of erodibility using soil strength and stress-strain indices for soils in some selected sites in Imo State". Research Journal of Environmental Earth Sciences, 2012, 4(7): $688-696$.

[8] D. B. Parker, T. G. Michel, and J. L. Smith, "'Compaction and water velocity effects on soil erosion in shallow flow". Journal of Irrigation and Drainage Engineering, 1995. ASCE 121(2): 170 - 178.

[9] M. A. Nearing and L. T. West, "Soil strength indices as indicators of consolidations". Trans. of the ASAE, 1988. 31(2): $471-475$. http://dx.doi.org/10.13031/2013.30733

[10] G. J. Hanson and K. R. Robinson, "The influence of soil moisture and compaction on spillway erosion"'. Trans. of the ASAE, 1993. 36 (5): $1349-1352$. http://dx.doi.org/10.13031/2013.28469

[11] G. J. Hanson, 'Erosion resistance of compacted soils. TRB. Transportation Research 1992, No. 1369: 26 - 30.

[12] G. J. Hanson, 'Effects of consolidation on soil erodibility". ASAE paper, 1993 no 93 - 2091. St. Joseph. Mich.

[13] G. J. Hanson, 'Development of a jet index to characterize erosion resistance of soils in earthen spillways". Trans. of the ASAE, 1991. 34(5): $2015-2020$.

http://dx.doi.org/10.13031/2013.31831 